\title{
QUALITY OF LIFE IN HONG KONG: THE CUHK HONG KONG QUALITY OF LIFE INDEX
}

\author{
(Accepted 15 August 2004)
}

\begin{abstract}
The CUHK Hong Kong Quality of Life Index, which aims to assess and monitor the quality of life in Hong Kong, is a composite index incorporating both objective and subjective measures. This index, developed by the Faculty of Social Science of The Chinese University of Hong Kong, employs data collected in representative sample surveys and official statistics. A wide range of life domains is covered and the year 2002 is taken as the base year of the study. Index scores demonstrate that in general the quality of life in Hong Kong has improved slightly in 2003; scores of the composite index and the three sub-indices on sectorial performance are somewhat higher than those of the previous year. It is noteworthy that Hong Kong has made noticeable progress and performs as well as many economically advanced societies in certain life domains; yet, the well-being of the people relies on further improvement in others.
\end{abstract}

KEY WORDS: quality of life, life satisfaction, well-being, life domains, social development

\section{INTRODUCTION}

Hong Kong, which has a total population of about seven million, has emerged as a highly modernized commercial center in East Asia over the last half century. Having been a British colony for a century and a half until its sovereignty was reclaimed by the People's Republic of China in 1997, Hong Kong has apparently achieved a high level of modernization and urbanization. After decades of rapid economic growth and urbanization, Hong Kong experienced the longest period of economic recession in its history subsequent to the outburst of the Asian financial crises in 1997, and is undergoing a drastic change in the 21 st century. In the face of an economic downturn, a budget deficit, income 
inequality, environmental pollution, and other problems, the quality of life in Hong Kong has been adversely affected. This is an appropriate time to compile a composite index to monitor the quality of life in Hong Kong.

It was not until the 1960s that 'quality of life' became an extensively discussed subject across academic domains and developed gradually into a major concern of the public and the government (Andrews, 1986; Diener and Rahtz, 2000; Diener and Suh, 2000; Veenhoven, 2000). Enhancement of quality of life is always amongst the foremost objectives in the course of social development; indicators of quality of life have been widely employed as measures of people's well-being, its achieved level, and changes over time. Extensive relevant literature in the past four decades reveals that researchers are not satisfied with works that assess the quality of human life and monitor the evolution of the societal environment in monetary terms alone (e.g., GNP). Researchers in general do not intend to relinquish conventional quantitative computation methods; yet, no universally accepted definition of 'quality of life', nor methods of its measurement have yet been established. Consequently, research on quality of life in most cases comes across two long-standing issues.

First, for the conceptualization of 'quality of life', there is no standard way of establishing the coverage of 'life'. Mainstream opinions in more advanced societies tend to differentiate 'quality of life' from 'standard of living'. Standard of living refers to the level of achieved satisfaction in basic materialistic needs. In addition to life chances and satisfaction in basic physiological needs, quality of life also covers satisfaction in emotional needs, such as being satisfied with freedom, justice, and opportunities for the complete development of individual capabilities. Therefore, quality of life research is concerned with an extensive range of topics, amongst which are: individual physical and mental health, well-being, satisfaction, family, work, housing, social relations, political and cultural lives, social ethics, and others. Consequently, researchers have never arrived at any consensus in the selection and weighting of indices in empirical quality of life studies. 
Second, views on how 'quality' should be assessed are rather diverse. Quality implies value judgments and ranking; consequently, quality of life might be ranked from high to low, and from improving to deteriorating. Theoretically, the ranking of quality should allow for longitudinal or cross-community comparisons, and conclusions such as "the quality of life in community X has been improved in the past decade", or "the quality of life in community A is better than that in community B'. Yet, there are no general rules governing the selection of 'judges' in the process of making the said value judgments. Hence, comparisons between communities or periods often prove difficult.

In general, quality of life studies can be grouped under two distinct orientations - the 'grass roots' approach or 'testimonial' model, and the 'means to quality of life' approach or 'ascriptive' model (Harwood, 1976; Shye, 1989). The 'grass roots' approach relies on people's judgments of needs and satisfactions according to individual life experiences and expectations. Researchers regroup and simplify the collected public opinions, and then construct a subjective framework on quality of life. It focuses on individual subjective feelings (such as degrees of satisfaction), in general and in specific life domains. Some representative studies of this orientation include the works of Andrews and Withey (1976), Campbell et al. (1976), and that of Campbell (1981). The model of Andrews and Withey takes both (1) values and criteria (for instance, the desires for success, safety, and an enjoyable life), and (2) conditions of life domains or role settings (for instance, work and family life) into consideration. It is assumed that these two sets of variables interact and affect an individual's perceived quality of life. A more comprehensive measurement of this kind has been developed more recently by the World Health Organization (1995): the Quality of Life Measure - WHOQOL-100 - takes account of 100 quality of life items.

The 'means to quality of life' approach relies on the expertise of the researchers. They define and analyze the needs of the people and decide accordingly the resources and means through which the quality of life of a particular population might be 
enhanced or otherwise under different conditions. In other words, inquiring into resources and objective conditions at individual, community, or societal levels constitutes a measure of quality of life. Elements being included in the measurement of quality of life and selections of indicators vary significantly amongst researchers. Examples of simple measures of quality of life include the Physical Quality of Life Index (which comprises literacy rate, infant mortality, and life expectancy) developed by Morris (1979) for the US Overseas Development Council, and the Human Development Index (which comprises life expectancy, educational level, and GDP) adopted by the United Nations (United Nations Development Programme, 2000). One example of a more complex index is the Index of Social Progress (Estes, 1998), which is composed of eleven sub-indices (education, health, women's status, national defense, economy, population, geography, political stability, political participation, cultural difference, and welfare) which encompass 44 indicators.

In the early 1980s, Bubolz et al. (1980) proposed a 'human ecological' approach which stressed the effects of interactions between individuals and environmental resources (including resources from natural, human constructed, and human behavioral environments) on the quality of life. Taking human values as benchmarks, Diener (1995) designed a composite quality of life index - the Combined QOL Index. The index incorporates both objective and subjective measures, which include basic physical needs, physicians per capita, suicide rate, subjective well-being, literacy rate, college/university attendance, gross human rights violation, income inequality, deforestation, major environmental treaties, homicide rate, monetary saving rate, purchasing parity power, and per capita income. More and more studies tend to agree on the importance of mutual influences between objective environmental conditions and the subjective feelings of individuals, and argue for the integration of objective and subjective indicators in assessing people's social progress and well-being, although there is no general consent about the principles that should be followed in the construction of these types of integrated indices. 
Researchers in Hong Kong are also aware of the importance of studies on quality of life in the enhancement of people's well-being. A number of local studies have contributed to the knowledge and assessment of the ever changing environmental conditions and the quality of life in Hong Kong. Among the prior work carried out by social scientists, two recent projects can represent the development of quality of life studies in Hong Kong. (1) The Hong Kong Institute of Asia-Pacific Studies (HKIAPS) of The Chinese University of Hong Kong launched the 'Indicators of Hong Kong Social Development' project in 1988. Since then, data on social development have been collected by sample surveys every two years (except for an interval of three years between 1990 and 1993). (2) At the turn of the century, the Hong Kong Council of Social Service (HKCSS) developed an index, the 'SDI2000', to measure the social development in Hong Kong.

The 'Indicators of Hong Kong Social Development' surveys conducted by HKIAPS employed subjective indicators which are based on the respondents' subjective perceptions and evaluations of their lives and experiences. Drawing on data collected in the surveys, two groups of the HKIAPS project members independently assessed the quality of life in Hong Kong. The first group analyzed the responses to individual questionnaire items relating to the subjective well-being of the respondents. The findings indicate that Hong Kong Chinese are more satisfied with their own personal lives than with societal conditions. The subjective well-being of respondents declined after 1995, although they are still generally satisfied with various aspects of their personal lives. In 1995, the majority of respondents felt that their standard of living was rising and they were optimistic about further improvements in the near future; yet, in 2001, nearly half of the respondents viewed the economic situation as being unsatisfactory and fewer than half of the respondents assessed their life as a whole in positive terms. In addition, as compared to their confidence in the national future, their confidence in the territory's future was significantly lower. It was also found that Hong Kong people considered good health, peace of mind, and money as the most important 
ingredients for a happy life; they had a strong desire for a better living environment and put great emphasis on education, considering it to be a major key to success (Wan and Wong, 1991; Wan, 1992, 1995, 1997, 2003). Employing the same set of questionnaire items, the second group examined the mean selfreported satisfaction level of individual life domains and attempted to develop a composite index to reflect changes in quality of life over the period from 1990 to 1997. To construct the global well-being index and the two sub-indices (the personal well-being index and the societal well-being index), Shen and Lai employed factoring (principal component) and optimal scaling methods instead of direct scaling in order to provide estimates for missing values and to increase the usable sample size. The constructed global well-being index indicates that the quality of life in Hong Kong declined from 1988 to 1995 and rebounded in 1997. For the economically inactive population, the rise and fall were more obvious. It was also found that the personal well-being index was more robust to the changes and only fluctuated very slightly with the global trend. On the other hand, the societal well-being index showed more obvious changes over time (Shen and Lai, 1997, 1999).

Unlike the HKIAPS indices, the social development index (SDI-2000) developed by the HKCSS relies on objective indicators which are based on measurements of observable conditions of social life. The basic SDI covers 14 sectors of development, which encompass 47 social, political, and economic indicators. In addition to weighted SDI scores which evaluated the overall social conditions and changes in Hong Kong between 1981 and 1998, HKCSS employed another 31 indicators to monitor social development patterns among women, the elderly, low income households, youth, and children. The SDI scores demonstrate steady and substantial advances in social development in the period, in particular, between 1991 and 1996. Among the 14 sectors of development, the performance of 10 sectors (science and technology, education, art and entertainment, internationalization, health, personal safety, strength of civil society, political participation, housing, crime, and public safety) was impressive, yet three 
sectors (economic, sports, and environmental quality) were making very slow progress, and one sector (family solidarity) was deteriorating. In addition, the social performance of women and the elderly was improving while that of low income households, youth, and children was in decline (The Hong Kong Council of Social Service, 2000).

It is undeniable that the studies mentioned above contribute significantly to knowledge of the quality of local life, yet they either rely solely on the respondents' subjective perceptions and evaluations of their lives and experiences (the indicators of Hong Kong social development surveys), or are based exclusively on objective measures of observable conditions of social life (SDI-2000). Their difference in approach leads to very obvious contradictory findings: the global well-being index of Shen and Lai depicts a downward trend between 1988 and 1995 while the SDI-2000 displays a continuous improvement between 1981 and 1998. Apparently, the unpredictability of subjective sentiment towards a particular objective condition is the major cause of such a disagreement between observations. Although researchers are generally in agreement that mutual influences between objective environmental conditions and subjective feelings of individuals are important and should be taken into consideration in the process of index construction, thus far an integrated index that incorporates both objective and subjective measures and continuously monitors changes in the quality of life in Hong Kong is still absent. In view of this, the Faculty of Social Science of The Chinese University of Hong Kong compiled the CUHK Hong Kong Quality of Life Index in 2003 to serve as an objective, comprehensive, and analytical tool to examine the quality of life in Hong Kong. The Index is released annually at the end of the year.

\section{CUHK HONG KONG QUALITY OF LIFE INDEX}

\section{Objectives}

The objectives of the CUHK Hong Kong Quality of Life Index are to: (1) measure and monitor the quality of life in Hong 
Kong in the 21st century; (2) engage relevant parties in promoting the quality of life in Hong Kong; (3) provide policymakers and the community with useful statistics on the quality of life in Hong Kong; (4) draw public attention to the issue of quality of life.

\section{Composition}

The CUHK Hong Kong Quality of Life Index is more comprehensive than other indices developed in local studies. It is a composite index incorporating both objective and subjective measures and consists of 21 indicators in three sub-groups, namely, the socio-cultural sub-index, the economic sub-index, and the environmental sub-index. The largest sub-group, the socio-cultural sub-index (10 indicators), is also the most multifaceted sub-group; it encompasses vital statistics, health statistics, press freedom statistics, political statistics, and crime statistics. The economic sub-index (seven indicators) covers statistics on employment, wages, the property market, public attitudes towards economic conditions, and education. The environmental sub-index (four indicators) comprises measures of air quality, water quality, noise level, and solid waste recycling. Hence, amongst the three sub-groups, the socio-cultural sub-index bears the heaviest weight in the composite index, while the environmental sub-index carries the lightest. These sub-indices allow for in-depth examination of important domains of public concern, while the composite index monitors the overall quality of life. (See Appendix A for grouping and operational definitions of the indicators.)

The indicators take in data collected in representative sample surveys and official statistics. A wide range of important life domains, including health, education, safety, freedom, housing, employment, and environmental quality are covered. Scores are either measurements at interval level or obtained by appropriate scaling methods. In other words, the indicators are selected according to their coverage, measurability, representativeness, and importance to the quality of life in Hong Kong. 
Among the 21 indicators, six are compiled by the Faculty of Social Science of The Chinese University of Hong Kong, namely, the stress index, the general life satisfaction index, the press freedom index, the press criticism index, the government performance index, and the index of current economic conditions. These six indices are measures of individuals' subjective feelings.

Four indices compiled by the Faculty draw on survey data collected in August 2002 and August 2003. In the surveys, the target population was adults aged 18 and above, and the data were collected through telephone interviews (computer assisted telephone interviews), employing identical structured questionnaires. Data on stress, general life satisfaction, press freedom, and government performance were collected from probability samples of Hong Kong residents $(n=1002$ in the 2002 survey, and $n=1004$ in the 2003 survey). The response rates were 45.2 percent and 43.2 percent, respectively. The margins of error are within \pm 3.01 percent and \pm 3.09 percent, respectively, at the 0.95 confidence level.

The year 2003 can be regarded as the worst year for Hong Kong since its reversion to China in 1997. It suffered not only a period of economic slowdown, but also an outbreak of Severe Acute Respiratory Syndrome (SARS) in the Spring of 2003, in addition to the tense political pressure due to the legislation of Article 23 of the Basic Law which was concerned with national security and was seen by many Hong Kong people as a threat to their personal freedom. All the discontent culminated in the mass demonstration of 500000 people on July 1. The event proved to be significant in the development of Hong Kong thereafter. It led to the postponement of the enactment of Article 23, the resignation of the Secretary of the Security Bureau of Hong Kong, and the re-organization of the SAR Government's Executive Council.

The survey on stress, press freedom, government performance, and general life satisfaction was conducted in August 2003, one month after the July 1 demonstration during which many people had vented their anger. After the demonstration, the government also became more responsive to people's demands despite being shocked by the event. 
Against this background, the survey showed that Hong Kong people in general considered that stress, press freedom, government performance, and their general satisfaction with life had all improved slightly compared with their situation one year earlier. Overall, the 'sense of triumph' felt by most Hong Kong people and the increased responsiveness of the HKSAR government after the July 1 demonstration might have contributed to the improved performance of these four socio-cultural sub-indices as well as the press criticism sub-index.

Information on press criticism was drawn from results of content analysis. In this analysis, the news reported by six local newspapers from August 2001 to July 2003 was sampled by the 'Constructed Sample Week' method. Each day from Monday to Saturday was randomly selected to construct a sample week in each month. After sampling all the newspapers, the contents were analyzed according to their news categories and major geographical locus of concern to measure the extent of press criticism of the Hong Kong Government, the PRC Government, and Hong Kong big business. Fifty samples were analyzed by all coders to determine the inter-coder reliability, which was above 70 percent for all key variables.

The index of current economic conditions is derived from the Quarterly Survey of Consumers that is conducted by the Department of Economics at The Chinese University of Hong Kong. Each quarter, the Department of Economics carries out a minimum of 500 telephone interviews (random samples). The respondents are asked to answer 10 questions, each of which represents various aspects of consumer expectations. Computation methods of these six indices are detailed in Appendix B.

The data on the remaining 15 indicators are obtained from public sources, which include the annual reports of the HKSAR Census and Statistics Department and those of the HKSAR Health Department (for vital statistics, crime statistics, and physical health statistics, etc.), and the quarterly reports of the HKSAR Census and Statistics Department (for wages, price indices, inflation rates, etc.). They are measures of objective environmental conditions. (See Appendix $\mathrm{C}$ for sources of specific statistics.) 
Taking the year 2002 as the base year of the study, the CUHK Hong Kong Quality of Life Index of 2002 is 100 (the sum of 21 indicators each carrying a base QOL value of 4.76). If the index of a year is above 100, it means that the quality of life in Hong Kong in that year is better than that in 2002. If it is below 100, it reveals that the quality of life in Hong Kong in that year is worse than that in 2002. If the index is 100, it indicates that the quality of life in Hong Kong in that year is the same as that in 2002 .

\section{FINDINGS OF THE CUHK HONG KONG QUALITY OF LIFE INDEX 2003}

According to the first CUHK Hong Kong Quality of Life Index released in November 2003, the preliminary score of the index of 2003 is 103.26 (See Table I). All three sub-indices on sectorial performance (socio-cultural, economic, and environmental sub-indices) are slightly higher than those in 2002, indicating that in general the quality of life in Hong Kong has improved slightly since 2002 .

Indicators of performance in different life domains are detailed below.

Socio-cultural sub-group

1. Standardized Mortality Rate: The standardized mortality rates, which are calculated by removing the effect of population composition, show that the Hong Kong population has the benefit of a stable and very low mortality $(<4.00$ per 1000 population). It is anticipated that socio-economic development and medical advancement will further reduce mortality, which is already among the lowest in the world, to a lower level in the years to come (Census and Statistics Department, 2002).

2. Life Expectancy at Birth: The life expectancies at birth for both sexes (84.83 for females and 78.84 for males) are comparable to economically advanced countries such as Sweden, Switzerland, and Japan. It is expected that the life expectancy at birth will increase by 4.1 for males and 3.8 for 


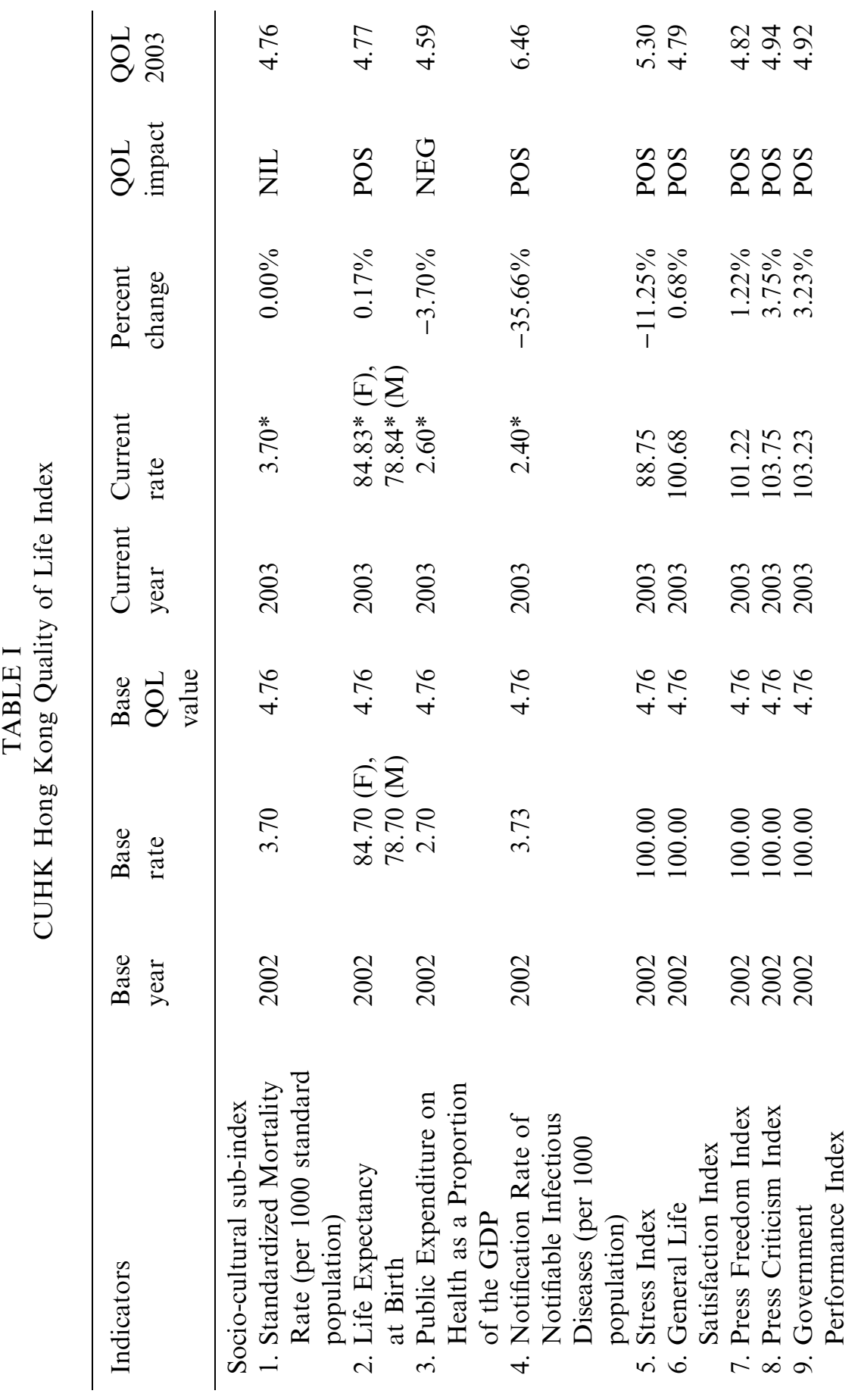




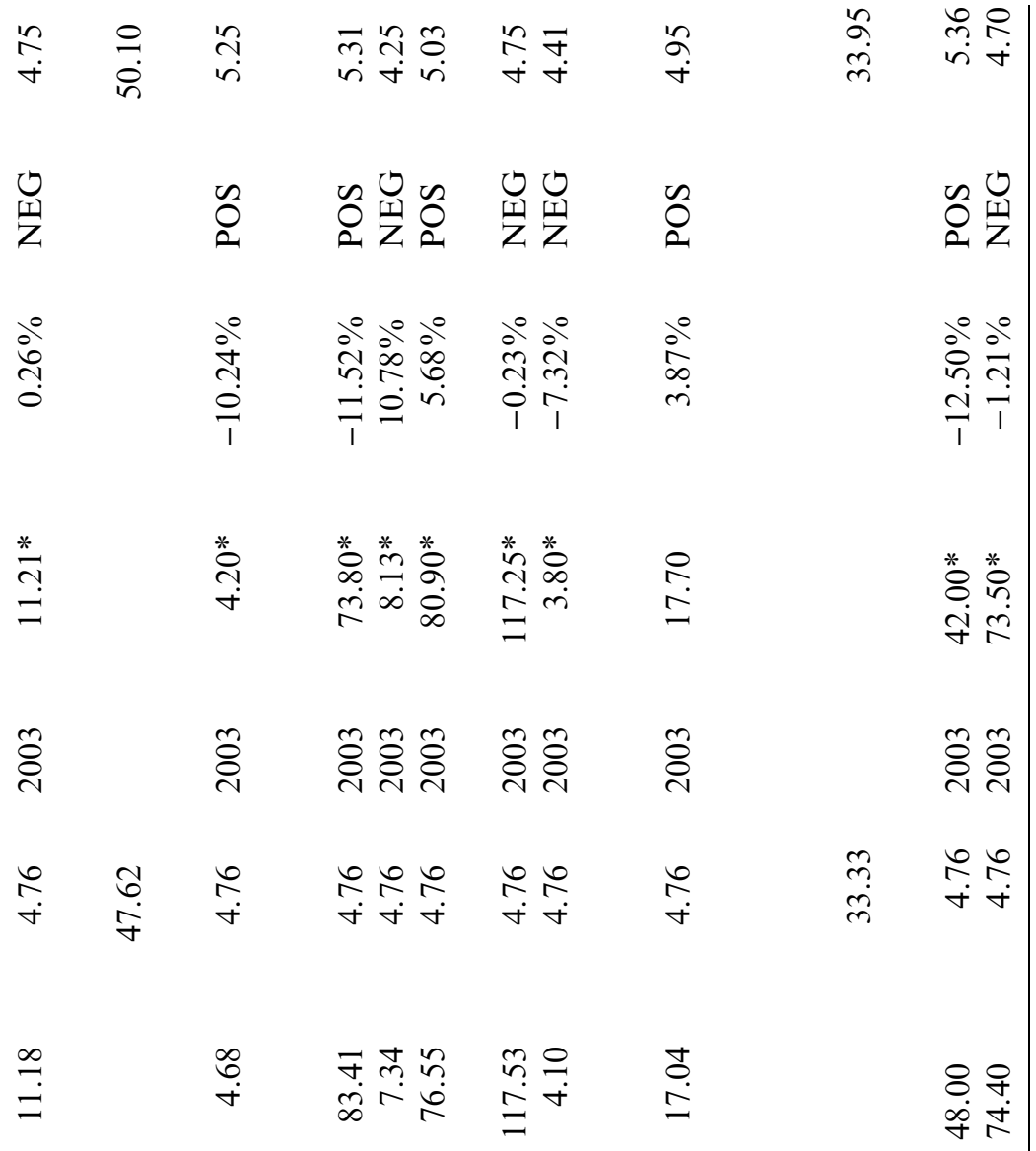

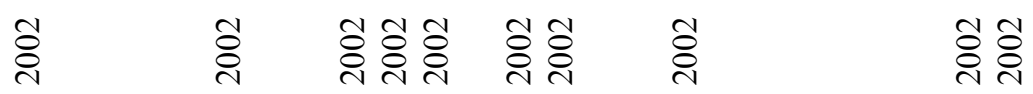

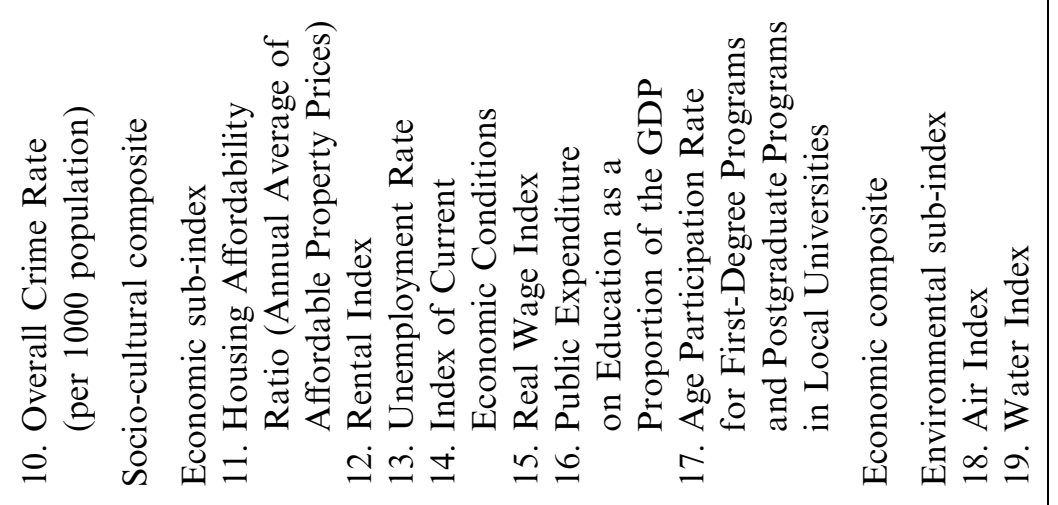




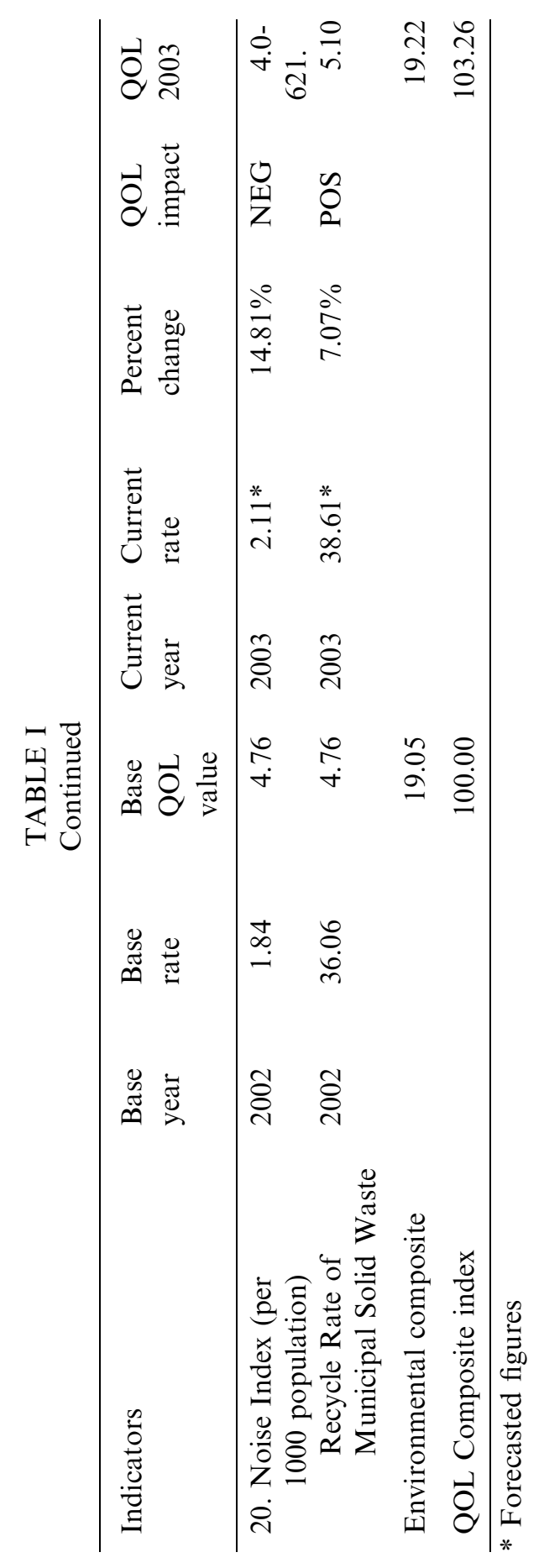


females over the next 30 years, owing to a further reduction in mortality (Census and Statistics Department, 2002).

3. Public Expenditure on Health as a Proportion of the GDP: As a result of the government's commitment to lowering the budgetary deficit in the next few years, public expenditure on health as a proportion of the GDP is forecasted to drop this year (2.60 percent). This figure is expected to be even lower in 2004 due to a combination of tighter fiscal policy and the economic recovery.

4. Notification Rate of Notifiable Infectious Diseases: Medical advancement and effective surveillance systems contribute to the low notification rates of 27 notifiable infectious diseases. The rates have declined steadily to a relatively low level in the past decade. The rate for 2003 remains low (2.40 per 1000 population) regardless of the outbreak of SARS early in the year.

5. Stress Index: Hong Kong people have become less stressed as compared to previous years. Nevertheless, people who show some symptoms of stress still significantly outnumber those who do not. Their proportions in the sample mark a gap of 17.96 percent.

6. General Life Satisfaction Index: There is no significant difference in proportion (1.03 percent only) between those who feel satisfied with life and those who do not. However, Hong Kong people in general considered their general satisfaction with life to be improved slightly compared with their situation one year earlier. It is obvious that life satisfaction cannot normally be improved much in a year's time, and the improvement from 2002 was only 0.7 percent for Hong Kong people.

7. Press Freedom Index: This sub-index, which tapped the subjective impression of respondents rather than the objective media contents as in the sub-index of press criticism, showed only a 1.2 percent improvement. Yet, it is noteworthy that people in Hong Kong generally feel that they can speak freely. The proportion of respondents who feel able to speak freely is greater (39.98 percent) than those who think otherwise. 
8. Press Criticism Index: The difference between the proportions of critical and uncritical reporting by the press on the Hong Kong Corporation, the HKSAR government, and the People's Republic of China Government is minimal (6.00 percent). Nevertheless the sub-index recorded more than 3 percent of improvement from 2002.

9. Government Performance Index: The majority of Hong Kong people are still not satisfied with the performance of the HKSAR government. There were 27.45 percent more respondents who indicated dissatisfaction than those who indicated satisfaction. However, the 'sense of triumph' of most Hong Kong people and the increased responsiveness of the government after the July 1 demonstration might have contributed to the improvement of more than 3 percent as compared to one year earlier.

10. Overall Crime Rate: Hong Kong people enjoy a relatively low overall crime rate. The overall crime rates showed a trend of continuous decline between 1992 and 2002 (Census and Statistics Department, 2003). Although the rate for 2003 (11.21 per 1000 population) is slightly higher than that for 2002, there is no clear evidence indicating an upturn in the overall crime rate.

Economic sub-group

11. Housing Affordability Ratio: The housing affordability index (currently 4.20) is expected to continue to decline, mainly due to a large reduction in house prices in the first three quarters of 2003. While a deflation in property prices is painful for some, it obviously makes housing more affordable for others. As regards the continuous downtrend of Hong Kong's house prices, it may have reached bottom in the third quarter of 2003. We expect a sharp rebound in property prices in 2004 as the Hong Kong economy heads for recovery, implying that housing will be less affordable next year.

12. Rental Index: The 2003 estimate (73.80) shows that the decline in the rental index continues. The outbreak of SARS, along with the relatively sluggish economy in the 
first half of 2003, are the main reasons for the weak performance of the 'tenants' market'. We anticipate an improvement in the 'tenants' market' in 2004, indicating an increase in rental index.

13. Unemployment Rate: The unemployment rate is likely to reach a historical high (8.13 percent) in 2003. A persistent increase in the unemployment rate for the past two years signals a serious deterioration in Hong Kong's labor market. However, the upward trend in the unemployment rate seems to be nearing an end, as the local economy is expected to display a speedy turnaround towards the end of 2003. The likely improvement in the domestic economy in the near future will give a boost to the local labor market that, in turn, will lead to a decrease in the unemployment rate in 2004.

14. Index of Current Economic Conditions (ICEC): The forecast for the ICEC this year is 80.90, up from 76.55 in 2002. Both households' financial conditions and consumer attitudes are expected to improve due to a sharp rebound in the local stock market in the second half of 2003. If the bullishness of the stock market can be extended to 2004, we are likely to see an upsurge in the ICEC next year.

15. Real Wage Index: The estimate of the real wage index for 2003 is 117.25 , a marginal dip from 117.53 in 2002 . We anticipate that real wages will not have a sharp turnaround next year unless the profitability of local firms shows a substantial improvement in 2004.

16. Public Expenditure on Education as a Proportion of the GDP: After reaching a new high (4.10 percent) in 2002, the public expenditure on education as a proportion of the GDP is expected to drop to 3.8 percent this year. This downtrend may continue for the next few years due to the reasons mentioned in (3).

17. Age Participation Rate for First Degree Programs and Postgraduate Programs in Local Universities: Subsequent to the expansion of tertiary education and the declining population of the younger age groups, the participation rates have improved in recent years. Yet, being an indicator 
of economic development, the current rate for Hong Kong (17.70 percent) is still below the World Bank standard for a First World industrial economy.

Environmental sub-group

18. Air Index: Like other large cities in this world, Hong Kong has suffered from a deterioration in air quality (currently at 48.00 level). The problem is a combination of factors including high population density, high rise buildings that hinder the air circulation at street level, and a high concentration of vehicles.

19. Water Index: The overall water quality in Hong Kong has improved in recent years (74.40 percent), but it is not enough for a clean bill of health because of the large population that translates into heavy environmental pressure.

20. Noise Index: A score of 1.84 per 1000 population in 2003 indicates that Hong Kong is probably one of the noisiest cities in the world. Traffic and construction are two major sources of noise pollution. It is an annoyance and a potential threat to public health. The problem is expected to be worse in the coming years.

21. Recycle Rate: Municipal solid waste (MSW) refers to domestic, commercial, and industrial wastes collectively. In 2002, Hong Kong recovered about 1.96 million tonnes of MSW that represented about 36.28 percent of the total MSW arising in the city. The rate was comparable to many major developed countries. The main kinds of recyclable wastes recovered included paper, plastics, and ferrous metal, which accounted for over 90 percent of the waste recovered.

Compared with the data from 2002, among 21 indicators, 12 indicators are better and seven are worse, while two remain unchanged. Six of the ten indicators in the socio-cultural subgroup have improved in 2003; they are the notification rate of notifiable infectious diseases, the stress index, the general life satisfaction index, the press freedom index, the press criticism index, and the government performance index. Two indicators, 
the standardized mortality rate and life expectancy at birth, show no obvious changes; and the remaining two indicators, public expenditure on health as a proportion of the GDP and the overall crime rate, are worse.

Among the seven indicators in the economic sub-group, four indicators show an improvement in 2003; they are the housing affordability ratio, rental indices, the index of current economic conditions, and the age participation rate for first-degree programs and postgraduate programs in local universities. At the same time, three indicators, the unemployment rate, real wage indices, and public expenditure on education as a proportion of the GDP, show deteriorations.

Whilst the majority of indicators in the above two subgroups demonstrate a general trend of improving performance, indicators in the environmental sub-group display divergence. Two indicators, the air index and the recycle rate of MSW, signal better environmental conditions, while the other two indicators in this sub-group, the water index and the noise index, show different trends.

\section{SUMMARY AND DISCUSSION}

Among the 21 quality of life indicators, six indicators illustrate that Hong Kong performs as well as many economically advanced societies in certain life domains: (1) the standardized mortality rate is among the lowest in the world; (2) Hong Kong people enjoy a long life span and the life expectancies at birth for both sexes are lengthening; (3) the notification rate of notifiable infectious diseases has declined steadily to a relatively low level; (4) the press freedom index indicates that people generally feel that they can speak freely; (5) the overall crime rate remains at a relatively low level; and (6) the recycle rate of recovered solid wastes is comparable to those of major developed countries.

In some other life domains, Hong Kong has made noticeable progress in the past decade. However, as a result of the government's pledge to lower the budgetary deficit, it is expected that the amount of public expenditure on health as a proportion of the GDP, and the amount of public expenditure on 
education as a proportion of the GDP will be lower in the next few years. Thus, provision of services in these two areas is likely to be affected.

Hong Kong is making progress, although it may be slight, in a number of life domains. Nevertheless, the well-being of the Hong Kong people relies on further improvement in these domains: (1) the stress index indicates that Hong Kong people are less stressed in 2003, yet the people who show some symptoms of stress still outnumber those who do not; (2) considering their lives in general, a significant proportion of Hong Kong people are not satisfied; (3) the press criticism index suggests that reporting in the local press is probably not critical enough; (4) the majority of Hong Kong people are not satisfied with the government's performance; (5) Hong Kong people have a more optimistic view of current economic conditions in 2003, but further improvement depends on the recovery of the Hong Kong economy; (6) the age participation rate for first-degree programs and postgraduate programs in local universities is still not up to the standard of advanced economies; and (7) water quality is improving, but further improvement is necessary.

In 2002 and 2003, deflation and lower prices made housing more affordable, and tenants enjoyed lower rents. However, the positive effects of the trends are only beneficial to some social groups; in addition, the trends are expected to turn around in 2004.

Hong Kong people are facing deteriorating living conditions in some aspects: (1) the unemployment rate is high in 2003, although it is expected to fall in 2004; (2) the real wage index lingers at a relatively low level as compared to the previous few years and a rapid augmentation seems unlikely; (3) air quality is deteriorating and there are no easy ways to eliminate factors that cause pollution; and (4) Hong Kong is one of the noisiest cities in the world and the situation is expected to worsen. Therefore, special efforts have to be made in order to reverse the trends in these areas.

The CUHK Quality of Life Index shows the quality of life in Hong Kong and trends of its development. The sub-indices 
facilitate assessments of performance in various life domains and the identification of areas which require substantial improvement; therefore, they provide useful references to policymakers and may serve as an important basis for evidencebased policy formulation.

The CUHK Quality of Life Index can be considered an improvement in two aspects when compared to prior work in Hong Kong. First, adopting an integrative approach, the CUHK Quality of Life Index encompasses both subjective and objective indicators and makes use of multiple types of data. Indicators which are based on objective measurements of observable social conditions are comparable to those included in the SDI-2000 of HKCSS, and indicators which are based on the respondents' subjective perceptions and evaluations are parallel to those covered by the HKIAPS surveys. Second, it is important to keep trend data across time. The CUHK Quality of Life Index has the advantage of maintaining regular updating.

At present, the CUHK Quality of Life Index is released annually at the end of the year. The compilation and release of the index can easily be accomplished bi-annually or even quarterly in the future, subject to availability of resources. Another possible extension of the index is to incorporate indicators that keep track of the quality of life in Hong Kong families, as family life impacts significantly on individual well-being.

\section{ACKNOWLEDGMENTS}

The research work on the CUHK Hong Kong Quality of Life Index was substantially supported by a grant from The Chinese University of Hong Kong.

Many members of the Faculty of Social Science, in particular, members of the Faculty's Sub-committee for the Celebrations of the 40th Anniversary of The Chinese University of Hong Kong, contributed to the development of the CUHK Hong Kong Quality of Life Index at various stages.

Special thanks go to Ms. Rachel Chan and Ms. Carmen Cheng, who have assisted us in the completion of this project. 


\section{APPENDIX A}

Composition of the CUHK Hong Kong Quality of Life Index

Socio-cultural sub-index

1. Standardized mortality rate (per 1000 standard population $^{\mathrm{a}}$ ) refers to the number of deaths per 1000 standard population

2. Life expectancy at birth (in years) refers to the life expectancy at birth for males and females

3. Public expenditure on health as a proportion (in percent) of the GDP

4. Notification rate of notifiable infectious diseases (per 1000 population) refers to the number of notified infectious diseases per 1000 population

5. Stress index refers to the stress that the Hong Kong people are facing (base rate $=100$ )

6. General life satisfaction index refers to the degree of satisfaction of Hong Kong people with their current lives (base rate $=100$ )

7. Press freedom index refers to the degree of press freedom in Hong Kong (base rate $=100$ )

8. Press criticism index refers to the frequency of criticisms by the press of the Hong Kong Corporation, the Hong Kong SAR Government, and the People's Republic of China Government (base rate $=100$ )

9. Government performance index refers to the degree of satisfaction of Hong Kong people with the performance of the Hong Kong SAR Government (base rate $=100$ )

10. Overall crime rate (per 1000 population) refers to the total number of violent and non-violent crimes reported per 1000 population

Economic sub-index

11. Housing affordability ratio refers to the annual average of affordable property prices (i.e. average property price times 39.9 sq. feet, divided by monthly medium income times 12 )

12. Rental index refers to the rental index for the Hong Kong property market

13. Unemployment rate refers to the seasonally adjusted unemployment rate (in percent)

14. Index of current economic conditions refers to the public attitude towards economic conditions in Hong Kong

15. Real wage index $^{b}$ refers to the real wages for employees up to supervisory level (excluding managerial and professional employees) in all selected industry sectors

16. Public expenditure on education as a proportion (in percent) of the GDP

17. Age participation rate for first-degree programs and postgraduate programs in local universities (in percent) 
APPENDIX A

Continued

Environmental sub-index

18. Air index refers to the daily air pollution index

19. Water index refers to the percentage of rivers in Hong Kong categorized as "good" and "excellent" by the monitoring station

20. Noise index (per 1000 population) refers to the number of noise complaints received by the Environmental Protection Department and the Police per 1000 population

21. Recycle rate of municipal solid waste refers to the recycle rate (in Percent) of solid waste from households and from commercial and industrial sources

${ }^{a}$ Standardized mortality rate is compiled based on the world standard population published in the 1997-1999 World Health Statistics Annual.

${ }^{b}$ As from 2001, the real wage index is derived by deflating the nominal wage indices by the 1999/2000-based CPI (A). To facilitate comparison, real wage index prior to 2001 has been re-compiled using the 1999/2000-based CPI (A) 


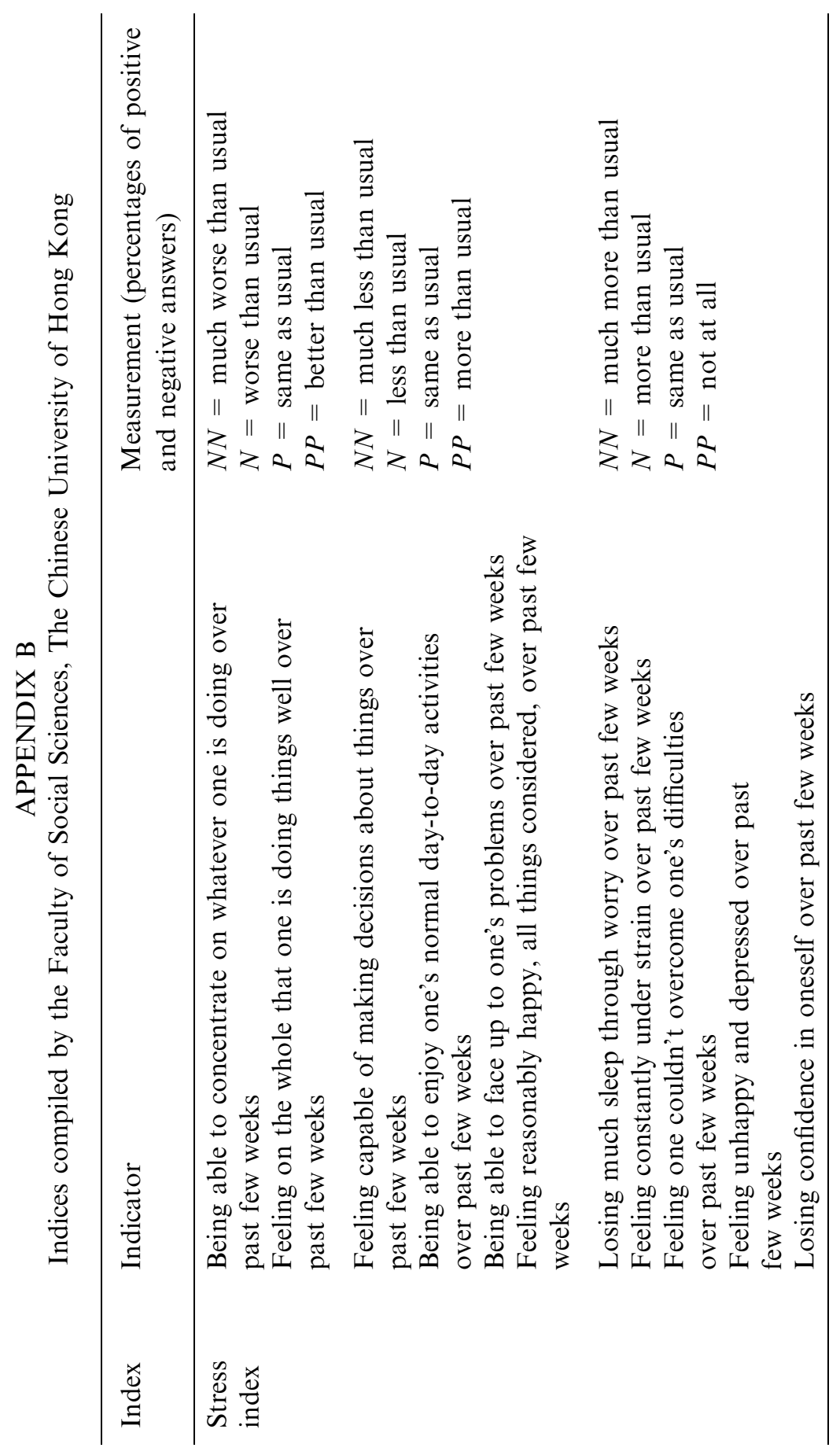




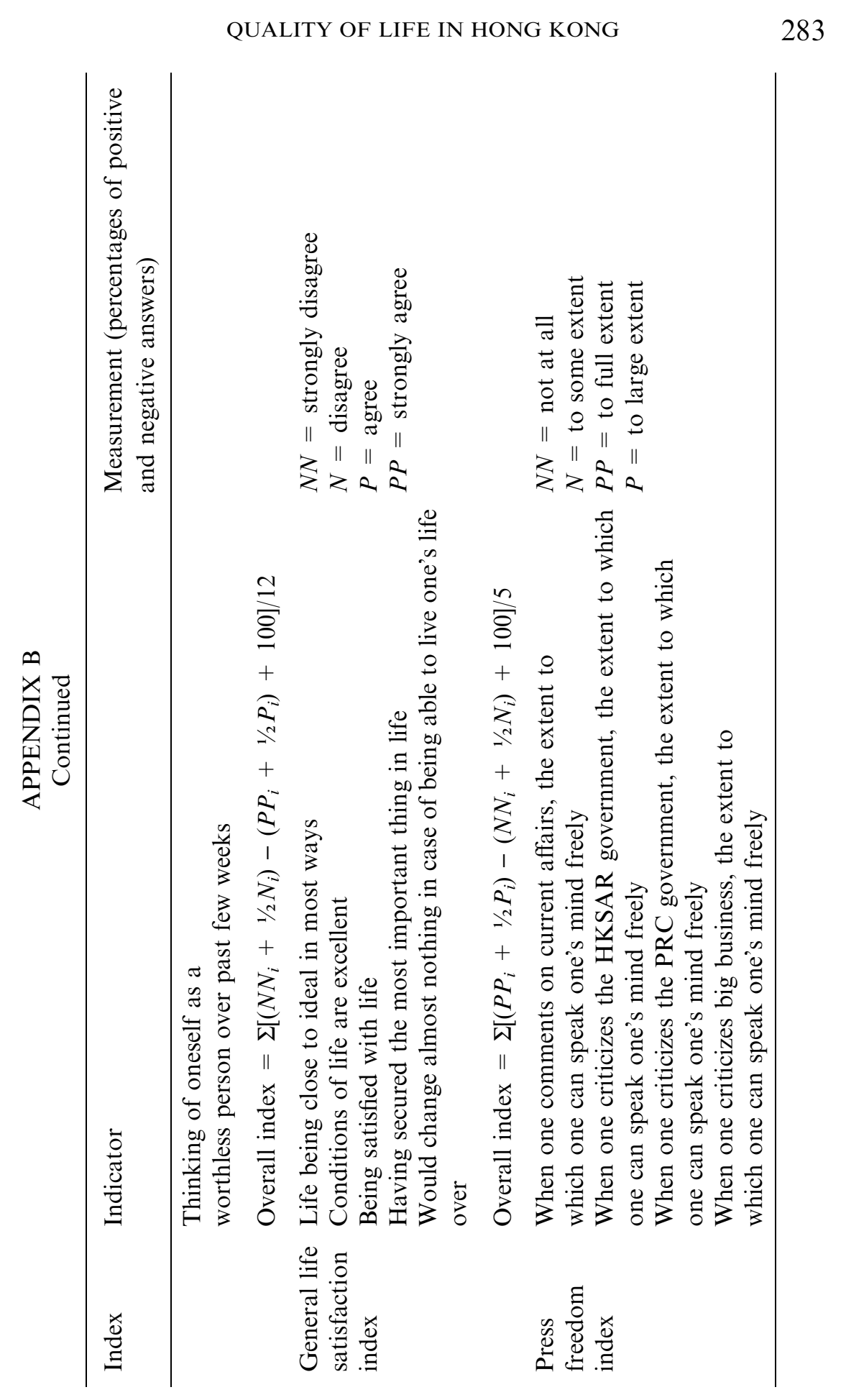




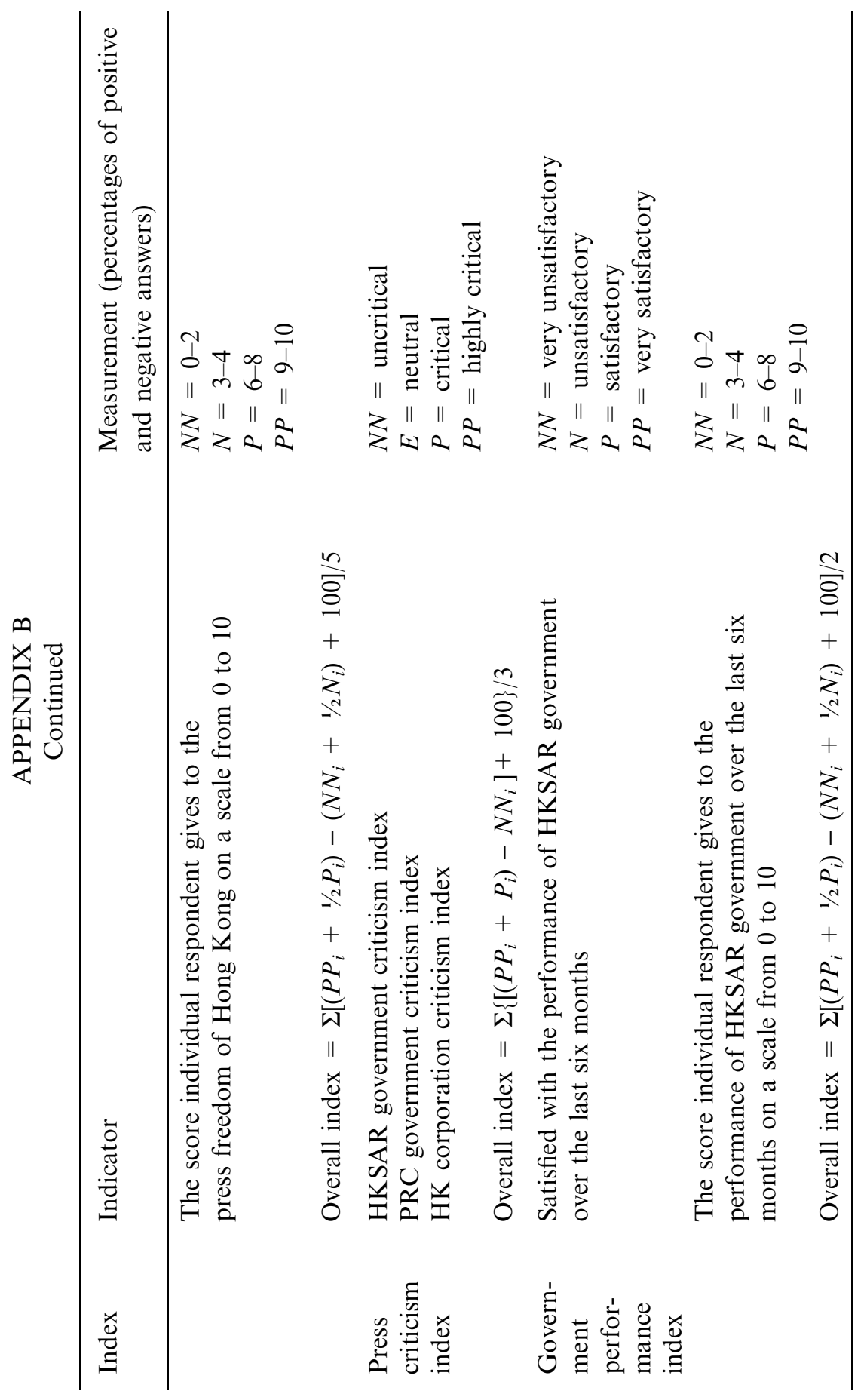




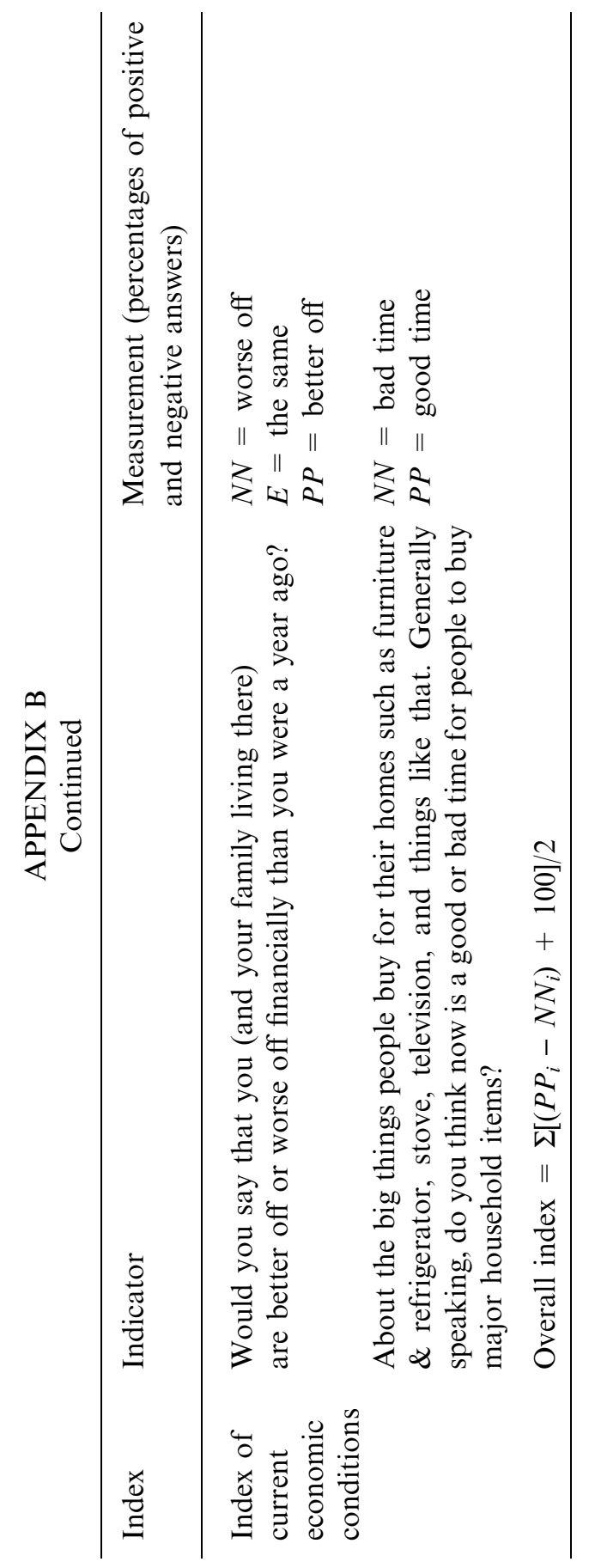


APPENDIX C

Indices obtained from public sources ${ }^{\mathrm{a}}$

Index
Standardized mortality rate
Life expectancy at birth
Public expenditure on health as
a proportion of the GDP

Notification rate of notifiable infectious diseases

\section{Source}

Various issues of Annual Report of Department of Health

Various issues of Hong Kong

Annual Digest of Statistics and

Hong Kong in Figures, Census and Statistics Department

Various issues of Hong Kong

Annual Digest of Statistics, Census and Statistics Department

www.budget.gov.hk

Various issues of Hong Kong

Annual Digest of Statistics, Census and Statistics Department

Various issues of Annual Report of Department of Health

Overall crime rate (per 1000

Various issues of Hong Kong

population)

Annual Digest of Statistics and

Hong Kong Monthly Digest of

Statistics, Census and Statistics

Department

Housing affordability ratio

Various issues of Hong Kong

Monthly Digest of Statistics and

Quarterly Report of General

Household Survey, Census and

Statistics Department

Rental index

Rating and Valuation Department http://www.info.gov.hk/rvd/property/

Unemployment rate Census and Statistics Department ${ }^{\mathrm{b}}$

Real wage index Census and Statistics Department ${ }^{\mathrm{c}}$

Public expenditure on education as a Various issues of Hong Kong proportion of the GDP

Age participation rate for Annual Digest of Statistics, Census and Statistics Department www.budget.gov.hk first-degree programs and University Grants Committee postgraduate programs http://www.ugc.edu.hk

in local universities

Air index

Air Quality Annual Report, Environmental Protection Department 


\begin{tabular}{ll} 
& $\begin{array}{c}\text { APPENDIX C } \\
\text { Continued }\end{array}$ \\
\hline Index & Source \\
\hline Water index & Environment Hong Kong 2003, \\
& Environmental Protection \\
Noise index & Department \\
& Environment Hong Kong 2003, \\
& Environmental Protection \\
Recycle rate & Department \\
& Environment Hong Kong 2003, \\
& Environmental Protection Depart- \\
& ment \\
\hline
\end{tabular}

${ }^{a}$ Official statistics for a particular year is usually obtainable from annual reports published in the year that follows. For example, the 2003 edition of Hong Kong Annual Digest of Statistics provides statistics up to year 2002. At the time the first CUHK Hong Kong Quality of Life Index was released, most official statistics for year 2003 were still unavailable. Therefore, forecasted figures derived from past trends were employed for the compilation of the provisional CUHK Hong Kong Quality of Life Index 2003

${ }^{b}$ http://www.info.gov.hk/censtatd/eng/hkstat/fas/labour/ghs/labour1_index. html

${ }^{\mathrm{c}} \mathrm{http}: / /$ www.info.gov.hk/censtatd/eng/hkstat/fas/wages/w_real_index.html

\section{REFERENCES}

Andrews, F. M. (ed.): 1986, Research on the Quality of Life (Institute for Social Research, University of Michigan: Ann Arbor).

Andrews, F. M. and S.B. Withey: 1976, Social Indicators of Well-being: Americans' Perceptions of Life Quality (Plenum: New York).

Bubolz, M. M., J. B. Eicher, S. J. Evers and M. S. Sontag: 1980, 'A human ecological approach to quality of life: Conceptual framework and results of a preliminary study', Social Indicators Research 7, pp. 103-136.

Campbell, A.: 1981, The Sense of Well-being in America: Recent Patterns and Trends (McGraw-Hill: New York).

Campbell, A., P. E. Converse and W. L. Rodgers: 1976, The Quality of American Life: Perceptions, Evaluations, and Satisfactions (Russell Sage Foundation: New York).

Census and Statistics Department, HKSAR: 2002, Hong Kong Population Projection: 2002-2031 (Government Printing Department, HKSAR: Hong Kong). 
Census and Statistics Department, HKSAR: 2003, Annual Digest of Statistics: 2003 Edition. (Government Logistics Department, HKSAR: Hong Kong).

Census and Statistics Department, HKSAR: 2004, Hong Kong in Figures: 2004 Edition (Government Logistics Department, HKSAR: Hong Kong).

Diener, E.: 1995, 'A value based index for measuring national quality of life', Social Indicators Research 36, pp. 107-27.

Diener, E.: and D. R. Rahtz (eds.): 2000, Advances in Quality of Life Theory and Research (Kluwer Academic Publishers: Dordrecht).

Diener, E.: and E. M. Suh (eds.): 2000, Culture and Subjective Well-being. (MIT Press: Cambridge, MA).

Estes, R. J.: 1988, Trends in World Social Development: The Social Progress of Nations, 1970-1987 (Praeger: New York).

Harwood, P. de L.: 1976, 'Quality of life: Ascriptive and testimonial conceptualization', Social Indicators Research 3, pp. 471-496.

Health Department, HKSAR: 2003, Annual Departmental Report: 2003 (Government Logistics Department, HKSAR: Hong Kong).

(The) Hong Kong Council of Social Service: 2000, Social Development in Hong Kong: The Unfinished Agenda (The Hong Kong Council of Social Service: Hong Kong).

Morris, M. D. 1979, Measuring the Condition of the World's Poor: The Physical Quality of Life Index (Pergamon Press: New York).

Shen, S. M. and Y. L. Lai: 1997 'Social well-being during 1988-1995: An index approach', in S. Lau, M. Lee, P. Wan and S. Wong (eds.), Indicators of Social Development: Hong Kong 1995 (Hong Kong Institute of Asia-Pacific Studies, The Chinese University of Hong Kong: Hong Kong), pp. 1-47.

Shen, S. M. and Y. L. Lai: 1999, 'Social well-being during the transitional period', in S. Lau, M. Lee, P. Wan and S. Wong (eds.), Indicators of Social Development: Hong Kong 1997 (Hong Kong Institute of Asia-Pacific Studies, The Chinese University of Hong Kong: Hong Kong), pp. 1-37.

Shye, S: 1989, 'Systemic life quality model: A basis for urban renewal evaluation', Social Indicators Research 21, pp. 343-378.

United Nations Development Programme: 2000, Human Development Report 2000 (Oxford University Press: New York).

Wan, P.: 1992, 'Subjective quality of life', in S. Lau, M. Lee, P. Wan and S. Wong (eds.), Indicators of Social Development: Hong Kong 1990 (Hong Kong Institute of Asia-Pacific Studies, The Chinese University of Hong Kong: Hong Kong), pp. 173-204.

Wan, P.: 1995, 'Satisfaction with life', in S. Lau, M. Lee, P. Wan and S. Wong (eds.), Indicators of Social Development: Hong Kong 1993 (Hong Kong Institute of Asia-Pacific Studies, The Chinese University of Hong Kong: Hong Kong), pp. 399-437. 
Wan, P.: 1997, 'Subjective well-being: now and then', in S. Lau, M. Lee, P. Wan and S. Wong (eds.), Indicators of Social Development: Hong Kong 1995 (Hong Kong Institute of Asia-Pacific Studies, The Chinese University of Hong Kong: Hong Kong), pp. 49-81.

Wan, P.: 2003, 'Subjective well-being', in S. Lau, M. Lee, P. Wan and S. Wong (eds.), Indicators of Social Development: Hong Kong 2001 (Hong Kong Institute of Asia-Pacific Studies, The Chinese University of Hong Kong: Hong Kong), pp. 321-344.

Wan, P. and S. Wong: 1991, 'Satisfaction in Various Life Domains,' in S. Lau, M. Lee, P. Wan and S. Wong (eds.), Indicators of Social Development: Hong Kong 1988 (Hong Kong Institute of Asia-Pacific Studies, The Chinese University of Hong Kong: Hong Kong), pp. 1-24. Veenhoven, R.: 2000, 'The four qualities of life: Ordering concepts and measures of the good life', Journal of Happiness Studies 1, pp. 1-39.

World Health Organization: 1995, WHOQOL-100 Facet Definitions and Questions. Geneva: Division of Mental Health, World Health Organization, $\mathrm{WHO} / \mathrm{MNH} / \mathrm{PSF} / 95.1 . \mathrm{B}$. Rev. 1.

Department of Sociology

The Chinese University of Hong Kong

Shatin, N.T.

Hong Kong

PR CHINA

E-mail:yingkchan@cuhk.edu.hk

Ying Keung Chan

Department of Economics

Cheuk Chiu Andy Kwan

The Chinese University of Hong Kong

Shatin, N.T.

Hong Kong

PR CHINA

E-mail:kwan1882@cuhk.edu.hk

Department of Social Work

Tan Lei Daniel Shek

The Chinese University of Hong Kong

Shatin, N.T.

Hong Kong

PR CHINA

E-mail:danielshek@cuhk.edu.hk 